\title{
Quality of Nursing Care among School Age Children with Thalassemia as Regards Blood Transfusion and Self Concept
}

\author{
Nagat Farouk Abolwafa ${ }^{1}$, Amal H. Mohamed ${ }^{2}$, Amany Anter Mohamed ${ }^{3, *}$ \\ ${ }^{1}$ Pediatric Nursing, Faculty of Nursing, Minia University, Egypt \\ ${ }^{2}$ Community Health Nursing, Faculty of Nursing, Minia University, Egypt \\ ${ }^{3}$ Psychiatric and Mental Health Nursing, Faculty of Nursing, Minia University, Egypt \\ *Corresponding author: medonoga13@yahoo.com \\ Received April 19, 2019; Revised June 15, 2019; Accepted July 01, 2019
}

\begin{abstract}
For children with major thalassemia, lifelong blood transfusions were need hence adequate care quality is crucial. Research aim was to improve quality of nursing care among school age children with thalassemia as regards blood transfusion and self concept. Research design: quasi-experimental design has been used. Study area: The study was done in out and inpatient pediatric unit at Minia University and General Hospitals. Study participants: purposive technique consisted of two category: the first participants are all nurses (13 Minia University nurses and 7 General Hospitals, total twenty nurse) and the second participant are fifty ill school children with thalassemia. Tools: Information were gathered by: face to face interviews questionnaire, including: sociodemographic data sheet for thalassemia, knowledge sheet for nurses and routine knowledge of blood transfusion (RBTKQ) questionnaire. (2) An observational checklist for evaluating thalassemia practices by nurses. (3) Scale of patient satisfaction. (4) The clarity scale of the self-concept. Results: This study showed significant improvements in post-test nursing knowledge and practices on thalassemia and blood transfusion and improved selfconcept in clients. Conclusion: After the program was applied, about thalassemia and blood transfusion now is understandable by nurses. The nurses considered the quality of nursing care and good self-concept. The research study suggested more studies to be done for improving nurses' knowledge and practices in the area of blood transfusion care and to improve the self-concept of thalassemia children.
\end{abstract}

Keywords: nursing quality, children in school age, thalassemia, transfusion of blood, self-concept

Cite This Article: Nagat Farouk Abolwafa, Amal H. Mohamed, and Amany Anter Mohamed, "Quality of Nursing Care among School Age Children with Thalassemia as Regards Blood Transfusion and Self Concept." American Journal of Nursing Research, vol. 7, no. 5 (2019): 670-676. doi: 10.12691/ajnr-7-5-1.

\section{Introduction}

Children born with significant thalassemia are naturally born, however they develop serious anemia in the first year of life. Other symptoms may include: facial bone deformity, fatigue, failure of growth, shortness of breath and yellow skin (jaundice) [1]. Beta-thalassemia major is a chronic blood disorder that affects life extensively and has hemolytic anemia, growth retardation, hepato-splenomegaly, and skeletal abnormalities. Pillitteri, [2] noted regular blood transfusions, iron chelation therapy and sometimes splenectomy are often required for its management also therapeutic regime is therefore complex, life-long and inconvenient, requiring repeated hospitalizations and transfusions of blood, which often adversely influences the child's physical and mental health.

Thalassemia management is life long, involving repeated transfusions of blood and chelation. These children have more negative self-conceptions than their normal counterparts.
[3]. Data on the psychosocial aspects of thalassemia major are scarce, however, controversial health care providers are more concerned with thalassemia medical management, probably because until about two decades ago, thalassemia children's lifespan was limited and the disease's medical problems were so severe. Now the psychosocial and behavioral problems are coming to the fore with increased life expectancy and improvement in thalassemia medical management [4]. Furthermore transfusion of blood is the cornerstone of individual care with major thalassemia and its primary objective is to enhance anemia and minimize inefficient erythropoiesis. There are fatal risks associated with transfusion of blood, despite its essential role to save life and improve the life of patients [5].

The formation of the concept of self during the developmental period of the individuals is found on the basis of the educational principles governing the family and the psychological, physical characteristics, and become a significant picture for them [6]. Many researchers believe that they will involve different positive or negative feelings to the extent that people find a 
comprehensive and definite self-concept or identity in their belief, inconsistent and desultory self-belief leads to many emotional issues $[7,8]$.

Quality of care indicates that the right things are being done correctly, improving results for patients, their families and their communities. It is also an efficient equilibrium between both the opportunities noticed and a structure of requirements and value systems. The quality of nursing care is crucial in terms of patient outcomes and safety $[9,10]$.

Nursing quality indicators involve: sufficient abilities, caring behaviours, clear communication, effective organizational and management systems, and effective involvement. Nurses need to understand that, unless the patient is satisfied, care can not be of high quality. Hence, customer satisfaction should remain a requirement for achieving healthcare goals [11]. In addition Ndambuki, [12] denoted that nurse should be aware of his / her responsibility for the quality of care given to patients, the institution, ethics and laws.

Educational nursing has practical and theoretical training that nursing staff are offered to prepare them as nursing experts for their responsibilities. It's very essential for nurses to participate in a lot of ongoing practice as well as keep changing patients' requirements and there are fresh developments in the procedure. Nurses ' training is never halted because fresh abilities and ideas must be continually mastered throughout their careers [13].

\subsection{Significant of the Study}

National Heart and Blood Institutes [14] stated that thalassemia is the most common genetically inherited hemoglobin disorder in Egypt with a carrier rate ranging from five point percent to more than nine percent.

For their treatment, school children with thalassemia frequently involve steady blood transfusions and iron chelation therapy. The therapeutic regime is therefore complicated and requires recurrent hospital admissions and blood transfusions for a life time, which often negatively impacts child's general health. Thus nurses with information and health-related thalassemia practices will enhance the quality of nursing care and enhance customer satisfaction and self-concept between those children.

\subsection{Aim of the Study}

To improve quality of nursing care among school age children with thalassemia as regards blood transfusion and self-concept

\section{Research Design}

Quasi-experimental design.

\subsection{Setting}

The study was done at Minia University and General Hospitals in-patient and outpatient pediatric departments.

\subsection{Subjects}

There was a purposeful sample of two groups: The first group consisted of all nurses (20) (13 nurses from Minia
University and 7 nurses from Minia General Hospitals), Nurses from $20->40$ years, nurses having experience from one to 20 years, both sex. The second group composed of children at school age with thalassemia major $(n=50)$, who attended the above-mentioned settings over a six-month period. The inclusion criteria: school-age children range from 6 to 12 years of both gender and exclusion of children suffering from other chronic medical conditions.

\subsection{Study Materials}

Tool I: Interview questionnaire constructed by researchers after the literature review. Three components included:

$1^{\text {st }}$ : Personal data for nurses as age, sex, marital status, qualifications and training, etc. School children, age, sex, level of education, and blood transfusion frequency / year.

$2^{\text {nd }}$ : Knowledge of nurses regarding thalassemia, such as meaning, reasons, clinical pictures and.........

$3^{\text {rd }}$ : Knowledge of regular blood transfusion questionnaire (RBTKQ), developed by Hijji, et al., [15] to evaluate the knowledge of nurses on blood transfusion. It comprised of 32 items that measure blood transfusion knowledge of nurses ( 2 true-false; 20 Multiple choices \& 10 questions that are open). This part assesses the knowledge aspects of collecting blood bags from blood bank and preparing patients before transfusion, nursing responsibilities for pre / post transfusion initiation, and blood transfusionrelated complications.

\section{Scoring system}

For the knowledge of the nurse about thalassemia and blood transfusion, the knowledge of the nurse was considered unsatisfied (less than 60 percent, while it was considered satisfied if 60 percent and more).

\section{Tool II:}

A- Observational blood transfusion checklist developed by Taylor, et al., [16], B-Evaluation of nursing practices related to body system assessment.

Scoring system: Every element was categorized into two rates; 'done' and 'not done', one mark for correct one, and zero for not done. Practice was considered unsatisfied (less than 60 percent) and satisfied (if 60 percent and more).

Tool III: Client satisfaction Scale (PSS): Risser [17] assessed patient attitudes towards nurses and nursing care and originally covered three subscales with a approximately 25 items described as:

1. Domain of Technical Professionals (TP) involves seven items on technical issues relating to the care and measurement of the behavior patterns of the nurse.

2. Domain of educational relationships ER) includes seven items specifically related to the nurse's attitude towards clients, sharing of information between them. The basic elements are: the nurse provides the right directions; the nurse always gives adequate clarifications as to why tests are requested, etc.

3. Domain of Trusting Relationship (TR) it is involves eleven items specifically to interpersonal nurse-patient relationship, verbal and nonverbal nurse-patient communication. The main components of this are; the nurse must be more friendly than she is, the nurse is individual who can know how I feel, the nurse is great to be around, etc. 
Scoring system: Each question is evaluated on a measurement scale of five-point Likert type ranging from strongly agreed (1) to strongly disagree (5). Positively and negatively sentences were involved in each sub-scale. The higher the score shows the patient's satisfaction with nursing care.

Tool IV: Clarification Scale of the concept of self: as written by Campbell, et al. [18] for self-concept evaluation, covered 12 statements, and its likert scale ranged from 1 (strongly disagreeable to 5 strongly agreed).

Scoring instructions: Less than 20 is low, moderate from 21 to 40 and is a high from 41 to 60 . Except for statements number 6 and 11 , the scale statements are reversed items.

\subsection{Effectiveness and Consistency of Instruments}

Repetitive test responses have been contrasted using Cronbach's alpha-coefficient method. The panel of 5 specialists evaluated the tools of the research.

\subsection{Ethical Issues}

The researchers clarified the study's objective for all respondents. Using the previously mentioned study tools, each subject was interviewed individually. They were informed that all data obtained used only for scientific reason. Respondent privacy was protected. They have been informed that there is voluntary involvement and that they can withdraw at any moment from the research paper.

\subsection{Educational Program}

It was designed to enhance the knowledge and practices of nurses about thalassemia and transfusion of blood, to improve the satisfaction and sufferer's personality-concept.

\subsection{Field Work}

The actual research work was carried out in the abovementioned settings from the beginning of October 2018 to the end of March 2019. The current research was carried out with formal approval from the study settings at Minia University and General Hospitals, clearly explaining the purpose and expected results of the study. Researchers were present in the work area at 9 a.m. to 12 p.m., twice weekly. It is important to stress that nature and purpose of the study was clarified and, the participant was informed of written consent. The time needed to implement the program was 6 months. One month for pre-/post-test, five months for program implementation. The study group attended eight sessions; four theory sessions and four practices sessions. The length of each session ranged from 30 to 45 minutes. The researchers started with a summary of the past session at the start of each session and explained the new objectives. Four theoretical sessions as follows: session 1, content: personal interview, purpose, duration of the researcher's explanation of the study through direct personal communication, and pre-test. The session 2, content: definition of thalassemia, causes, manifestations, types. The session 3, content: treatment and complications on body systems. The session 4, content: Nurse's knowledge about blood transfusion. 4 sessions for practice the session 1, content: Nurse's practice regarding blood transfusion, the session 2: assessment of the body system, the session 3: Measurement of $\mathrm{v} / \mathrm{s}$ and session 4: intravenous iron therapy. Lecture, discussion for theory part and demonstrations for practical one. The learning facilities that used were handouts, colored leaflets and display of the laptop screen. The training and educational sessions were conducted while the patients were in the patient unit and followed up on the outpatient clinic. A copies of all the instructional materials included within the program booklet shall be provided to each participant. Evaluation of outcome of the training program was carried out by researchers after program implementation using assessment interview questionnaire to examine the effect of program.

\subsection{Statistical Design}

The data analysis was carried out using SPSS-21 of statistical software. Descriptive analysis, T- test and Chisquare were used.

\section{Result}

Table 1. Distribution of study characteristics of nurses $(n=20)$

\begin{tabular}{|l|c|c|}
\hline & No & \% \\
\hline $\begin{array}{l}\text { Age (in years): } \\
20: 30\end{array}$ & 6 & 30 \\
\hline $31: 40$ & 9 & 45 \\
\hline$<40$ & 5 & 25 \\
\hline Mean \pm SD & $33.20 \pm 6.25$ \\
\hline $\begin{array}{l}\text { sex: } \\
\text { Male }\end{array}$ & 3 & 15 \\
\hline Female & 17 & 85 \\
\hline $\begin{array}{l}\text { Educational level } \\
\text { Nursing diploma }\end{array}$ & 6 & 30 \\
\hline Technical institute & 8 & 40 \\
\hline Bachelor degree & 6 & 30 \\
\hline $\begin{array}{l}\text { Years of experience } \\
1: 5 \text { years }\end{array}$ & 11 & 55 \\
\hline $5: 10$ years & 6 & 30 \\
\hline$<10$ years & 3 & 15 \\
\hline $\begin{array}{l}\text { Thalassemia and blood transfusion training } \\
\text { Yes }\end{array}$ & 0 & 0 \\
\hline No & 20 & 100 \\
\hline
\end{tabular}

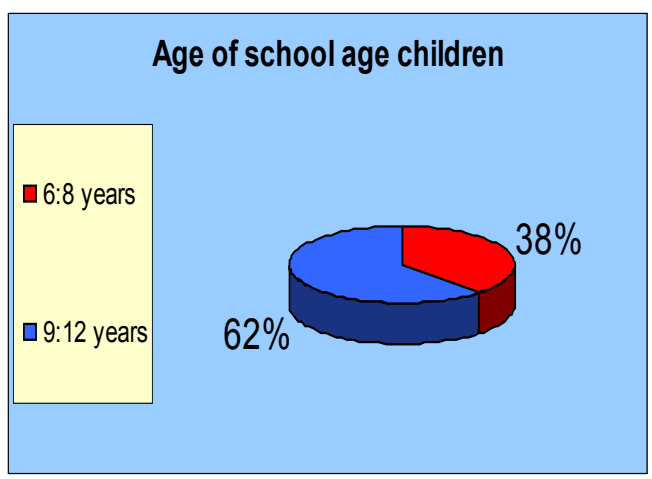

Figure 1. Age of school age children 


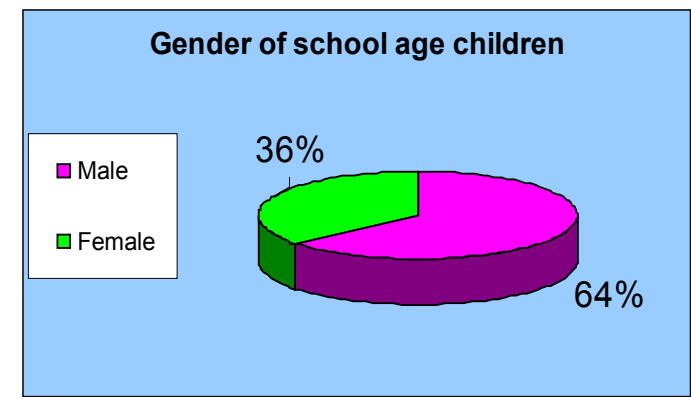

Figure 2. Gender of school age children

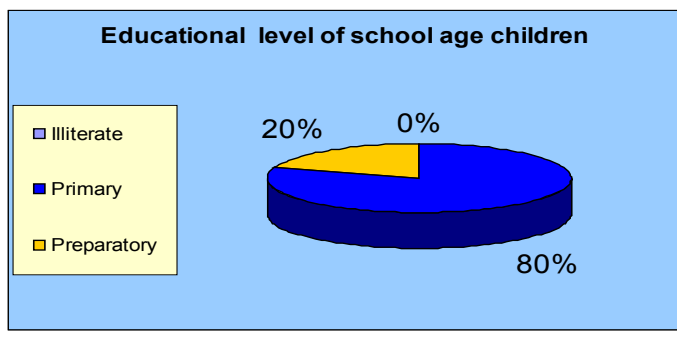

Figure 3. Educational level of school age children

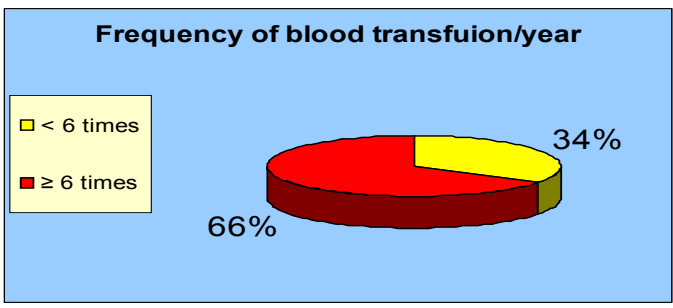

Figure 4. Frequency of blood transfusion/ year
Figure 1, Figure 2, Figure 3, and Figure 4 distribution of socio-demographic characteristics of school-age children and blood transfusion frequency $(n=50)$.

Table 1 \& Figure 1, Figure 2, Figure 3, and Figure 4 show the distribution of the nurses according to characteristics. $45 \%$ of nurses were in the age group of $31: 40$ years with mean age was $33.20 \pm 6.25$. As regards gender, $85 \%$ of nurses were female, $40 \%$ had a technical institute, and $55 \%$ of nurses had 1:5 years of pediatric inpatient experience. While $100 \%$ of them did not receive thalassemia and blood transfusion training, while, the mean age of school children from 9:12years with thalassemia was $10.20 \pm 2.25,64 \%$ were males. Sixty six percent received blood transfusion 6 times or more per year.

Table 2 illustrates that the pre/post program distributes knowledge of thalassemia and blood transfusion to nurses. Improved the overall mean score of pre / post program knowledge of nurses (from $39.21 \pm 23.14$ to $62.24 \pm 16.24$ ); respectively. Statistically significant differences between pre/post program $P$ value (0.01).

Table 3 demonstrates that pre-/post-program results in all nursing practice items were highly statistically significant $(\mathrm{P}<0.00)$, total nursing practice scores for school-age children with thalassemia, these were a highly statistically significant improvement between the implementation of the pre /post program (39.21 \pm 15.6 to $74.08 \pm 16.22)$.

Table 4 summarizes that there are statistically significant difference between poor, moderate, and good satisfaction regarding to quality of nursing care pre/post program implementation (P. 0.02, 0.01, and 0.03); respectively.

Table 2. Distribution of nurses knowledge regarding thalassemia and blood transfusion pre/post program implementation $(\mathrm{n}=\mathbf{2 0})$

\begin{tabular}{|l|c|c|c|c|}
\hline Items & $\begin{array}{c}\text { Pre test } \\
\text { Mean } \pm \text { SD }\end{array}$ & $\begin{array}{c}\text { Post test } \\
\text { Mean } \pm \text { SD }\end{array}$ & T- test & P. value \\
\hline Meaning of thalassemia & $6.4 \pm 3.3$ & $8.0 \pm 2.2$ & 5.3 & $.01^{*}$ \\
\hline Thalassemia manifestation & $5.3 \pm 2.1$ & $7.1 \pm 1.3$ & 7.4 & $.01^{*}$ \\
\hline Etiology of thalassemia & $6.2 \pm 4.2$ & $7.6 \pm 2.3$ & 10.1 & $.01 *$ \\
\hline Types of thalassemia & $5.3 \pm 2.4$ & $8.3 \pm 3.2$ & 6.3 & $.01^{*}$ \\
\hline Patient management and instructions & $6.1 \pm 5.0$ & $8.4 \pm 2.3$ & 3.2 & $.01^{*}$ \\
\hline Complications of thalassemia & $2.3 \pm 2.2$ & $7.1 \pm 1.3$ & 5.3 & $.01^{*}$ \\
\hline Importance of transfusion of blood & $4.3 \pm 2.0$ & $9.6 \pm 3.5$ & 6.4 & $.01^{*}$ \\
\hline Blood transfusion adverse effects & $5.2 \pm 3.3$ & $8.3 \pm 2.3$ & 6.6 & $.01^{*}$ \\
\hline Total knowledge & $39.21 \pm 23.14$ & $62.24 \pm 16.24$ & 12.2 & $.01^{*}$ \\
\hline
\end{tabular}

$*=$ Significant.

Table 3. Distribution of nurses regarding their practices pre / post program implementation $(n=20)$

\begin{tabular}{|c|c|c|c|c|}
\hline Items & $\begin{array}{c}\text { Pre test } \\
\text { Mean } \pm \text { SD }\end{array}$ & $\begin{array}{c}\text { Post test } \\
\text { Mean } \pm \text { SD }\end{array}$ & T- test & P. value \\
\hline Examination of the body systems & $6.4 \pm 2.8$ & $10.3 \pm 4.1$ & 5.2 & $.000 *$ \\
\hline Measurement of vital signs & $7.3 \pm 3.3$ & $13.4 \pm 2.5$ & 7.6 & $.000 *$ \\
\hline Administration of IV iron chelation therapy & $8.3 \pm 2.5$ & $12.4 \pm 2.3$ & 6.2 & $.000 *$ \\
\hline Nursing role in preparatory phase of blood transfusion & $6.4 \pm 3.2$ & $14.2 \pm 4.4$ & 7.3 & $.000 *$ \\
\hline Responsibility for nursing during blood transfusion & $5.2 \pm 3.5$ & $12.3 \pm 2.5$ & 6.4 & $.000^{*}$ \\
\hline Nurses role after transfusion of blood & $7.5 \pm 2.7$ & $13.3 \pm 2.5$ & 4.8 & $.000^{*}$ \\
\hline Total practices & $39.21 \pm 15.6$ & $74.08 \pm 16.22$ & 12.3 & $.000^{*}$ \\
\hline
\end{tabular}

*=Significant. 
Table 4. Distribution of school children satisfaction scale pre/post program implementation no= 50

\begin{tabular}{|c|c|c|c|c|c|c|}
\hline \multirow[t]{2}{*}{ Scale of school children satisfaction } & \multicolumn{2}{|c|}{ Pre- test } & \multicolumn{2}{|c|}{ Post-test } & \multirow{2}{*}{ T. test } & \multirow{2}{*}{ P. value } \\
\hline & No & $\%$ & No & $\%$ & & \\
\hline - Poor satisfaction with the quality of nursing & 42 & 84 & 7 & 14 & 5.3 & $0.02 *$ \\
\hline -Moderate satisfaction with the quality of nursing & 6 & 12 & 36 & 72 & 6.2 & $0.01 *$ \\
\hline -Good satisfaction with the quality of nursing & 2 & 4 & 7 & 14 & 4.2 & $0.03 *$ \\
\hline
\end{tabular}

$*=$ Significant.

Table 5. Distribution of the self-concept clarity scale pre/post program implementation no= $\mathbf{5 0}$

\begin{tabular}{|c|c|c|c|c|c|c|}
\hline \multirow{2}{*}{ The self-concept clarity scale } & \multicolumn{2}{|c|}{ Pre- test } & \multicolumn{2}{|c|}{ Post-test } & \multirow{2}{*}{ T. test } & \multirow{2}{*}{ P. value } \\
\hline & No & $\%$ & No & $\%$ & & \\
\hline - Low self-concept & 12 & 24 & 2 & 4 & 4.3 & $0.01 *$ \\
\hline - Moderate self-concept & 36 & 72 & 44 & 88 & 5.2 & $0.03 *$ \\
\hline - High self-concept & 2 & 4 & 4 & 8 & 5.3 & $0.04 *$ \\
\hline
\end{tabular}

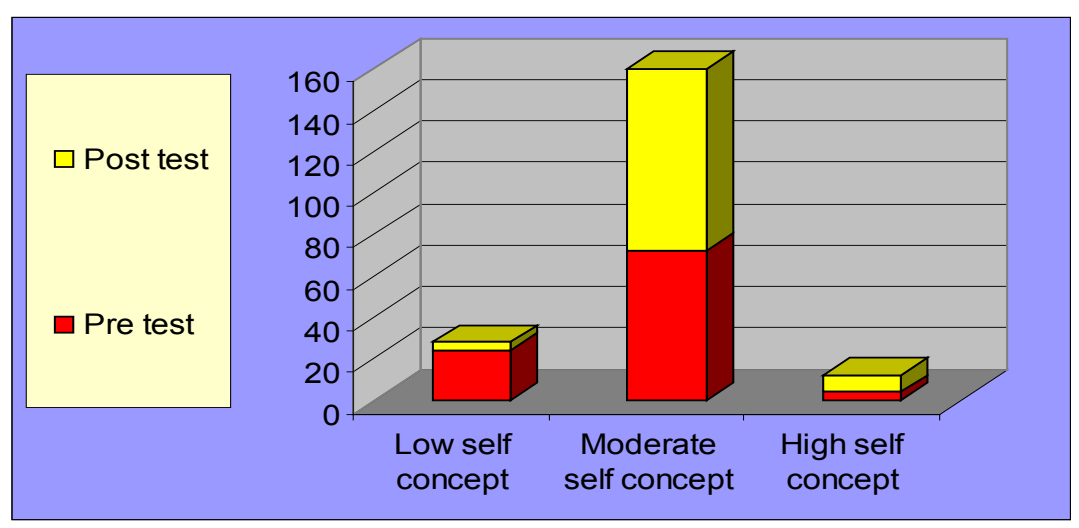

Figure 5. Distribution of the self-concept clarity scale pre/post program implementation no $=50$

Table 5 \& Figure 5 explains that most school-age children with thalassemia had a low self-concept in the pre-test $24 \%$ and $4 \%$ in the post-test, $72 \%$ in the pre-test and $88 \%$ in the post-test and $4 \%, 8 \%$ has a high self-concept respectively in pre/pos. There is also a statistically significant difference between them.

Table 6. Correlation between overall scores of nurses knowledge and practices in pre/ post-test program implementation $\mathbf{n}=\mathbf{2 0}$

\begin{tabular}{|l|c|c|}
\hline \multirow{2}{*}{ Pre-test } & \multicolumn{2}{|c|}{ Post-test } \\
\cline { 2 - 3 } & Correlation Coefficient (r) & P. value \\
\hline Knowledge & 0.96 & $0.000^{*}$ \\
\hline Practices & 0.98 & $0.000^{*}$ \\
\hline
\end{tabular}

*=Significant.

Table 6 illustrates that the knowledge and practices of nurses are positively highly correlated.

\section{Discussion}

Globally, there are 350,000 annual births with serious hemoglobinopathies [5]). Additionally, nursing staff are necessary to help thalassemic sufferers become conscious of their own condition teaching effective self-management techniques, preventing complications and transferring pediatric patients to the healthcare team and genetic counseling [19].

In our study, less than half percent of nurses their age ranged from 31:40 years, 1:5 years of experience, and are educated at the level of the technical institute. Elewa \&
Ahmed, [20] said that almost half of them were between the ages of $30-<40$, more than two-fifths of them had less than five years of experience and less than three-quarters were graduates who could elaborate on the current state of nursing qualifications, followed by graduates of technical institutes. These results were in line with that of the research by Elkattan [21], which discovered that over twothirds of the total sample under research had less than ten years of experience. It can be clarified by the fact that the 'most prevalent age group of nurses ranges from $18-<30$ years.

Current study showed all nurses have not attended an education program on thalassemia and blood transfusion. This could be attributed to a shortage of clinical nursing staff preventing them from attending any training courses to avoid work interruption. The results of a study conducted by Elewa \& Ahmed [20] supported this finding, who stated that, more than two thirds of studied nurses who didn't attend training program related to disease and blood therapy. And in agreement with Salem [22], who stated that more than three quarters of nurses did not receive any training courses.

The current research as for school age children with thalassemia features, children from 9:12 years of age are over half of school age. These study results agree with Elewa \& Ahmed, [20] who said two-third of research respondents' were under the age of 12 .

Over half of the children with thalassemia were male it is important to said that thalassemia is a blood genetic disorder that affects men and women alike. The result of this study does not agree with Elewa \& Ahmed, [20] who said that females were affected more than males. 
The current research shows that most samples receive equal blood transfusion more than six times a year. This relates to the reality that for individuals with chronic thalassemia, blood transfusion is the first line that prevents most severe circumstances. This research is in line with the Northern California Comprehensive Thalassemia Center [23], which reported that the transfusion therapy goal was to allow ordinary growth and development. Splenomegaly, hypersplenism, and dietary iron absorption will also be reduced by adequate transfusion treatment. And in agreement with Elewa \& Ahmed [20], who stated that most of the study sample receives equal blood transfusion more than six times per year, this recommended that blood transfusion is the first and primary line of care for clients with significant thalassemia to avoid severe deterioration in client circumstances.

This research discovered a considerable enhancement after teaching program in all nurses ' understanding and skills, which led to enhanced results for patients. This improved performance can be attributable to several rationales, such as refreshment of information through program sessions, usefulness of program content, clarification, simplicity of program components and language This result is in line with Aslani et al. [9], Which demonstrated that the knowledge and skills of nurses to use needles with an appropriate diameter was good but lacked accurate and scientific knowledge of blood heating indications and methods. Khouri, [24] also founded that education could enhance nurses' ability to be effective caring practitioners. Furthermore, Hijji et al. [15] pointed out that prevention and recognition of a transfusion reaction requires adequate knowledge from nurses.

Aslani et al., [9] stated that inadequate knowledge of the studied nurses prior to teaching sessions may be due to a lack of preparation during basic education or lack of desire of nurses to gain new knowledge, the overload in the workplace and the lack of ongoing blood transfusion thalassemia-related education courses. Nurses play a significant role in the right, technical and secure use of blood, and its product.

There have been statistically significant variations in nursing practice between pre- and post-educational programs. In the same way, the incompetence in the level of practice of nurses before the educational program is implemented this may be due to lack of supervision, neglect, shortage by nurses. Alomar [25] and Deborah and Corcoran [26] supported our study's results, who stated that nearly two-thirds of the study nurses had unsatisfactory practice with respect to the total nursing practice of patient management during nursing evaluation.

Patient satisfaction is widely accepted as a good indicator of the quality and efficacy of nursing care. The results of this research showed that most customers were not satisfied with the quality of the nursing care in pre-test program, which improved after the post-test. These might be linked to the efficacy of the instructional program reflecting on the improvement of nurses' understanding and procedures, which in turn may influence patient results and satisfaction. This result was agreed with Ndambuki [11], who disclosed that the quality of care given to children could be improved through education of nursing science.

This study revealed that most school-age children with thalassemia had low and moderate self-concept in pre-test, while most school-age children have moderate and high self-conceptions in post-testing. This result of the study is coherent with Karimi and Memarzadeh, [27] who noted that logo treatment was efficient in enhancing self-conception.

Research findings are consistent with the research results of [8] which indicated an increase overall health and positive self-concept and attempted to act responsibly in response to challenges.

Research shows that children with chronic diseases lacking social support have low self-concept and body image distorted. Messina [28], needed to add that in chronic diseases such as thalassemia, especially in children, psychological aspect is very important. It should also be noted that thalassemia children face more psychopathological disorders like negative body image. Researchers suggest that children with chronic diseases will better adapt to the disease if they have a positive self-concept [29].

Current result demonstrated a statistically significant correlation between the knowledge score, nursing practices and age, the years of experience. This may be due to the fact that 40 percent of the nurses studied had a technical nursing institute that could elaborate on the current nursing qualification condition. These research results were supported by Deborah and Corcoran, [1] who disclosed a positive association between the knowledge of nurses, the practice of nursing.

The research finding revealed a statistically significant correlation between the general understanding and procedures of nurses, which confirm a favorable connection between them. On other hand, without adequate knowledge transfusion may be initiated by nurses at a rate that is either slower or faster than recommended. This finding of the study is in line with Hunter [30], who identified that most importantly, nurses can learn as many skills as possible, and they should include the abilities in their care.

\section{Conclusion}

The application of the teaching program had a beneficial impact on nurses ' knowledge and practices in children of school age related to thalassemia and blood therapy Which enhance quality of their skills, clients received proper quality of care and self-concept.

\section{Recommendations}

A specialized orientation program should be developed for newly nurses to be prepared for working in pediatric unit. More research to enhance nurses' understanding and procedures regarding blood transfusion and care for thalassemic children should be conducted. Develop and implement an in-service nursing training program that highlights the weaknesses as psychosocial elements of thalassemia.

- For some practical implications, further studies are suggested to improve and invest in psychosocial aspects (self-concept, self-esteem, social support and .....) to strengthen and estimate the mental and social well-being of those suffering from chronic disease as thalassemic children. 


\section{References}

[1] DeBaun, M.R., Glauser, T.A., Siegel, M., Borders, J., \& Lee, B. (2011). Noninvasive central nervous system imaging in sickle cell anemia: A preliminary study comparing transcranial, Doppler to magnetic resonance angiography. American Journal of Pediatric Hematology/Oncology; 17, 29-33.

[2] Pillitteri, A. (2014). Maternal \& child health nursing, care of the child bearing $\&$ childrearing family (7th ed.). Lippincott: Williams, \&Wilkins, p.1289.

[3] Moorjani JD, Issac C. Neurotic manifestations in adolescents with thalassemia major. Indian J Pediatr 2006; 73: 603-7.

[4] Kumar N, Singh J, Khullar H, Arora M. (2018). Cross sectional study to assess behavioral problems in multi-transfused thalassemic children and psychosocial factors affecting them. International Journal of Contemporary Pediatrics, 5(3): 839-842.

[5] Soc Guidelines. (2012). Standards of care guidelines for thalassemia, Children's Hospital \& Research Center Oakland Hematology/Oncology Department. Available at:

www.childrenshospitaloakland.org.

[6] Harter, S., Processes underlying adolescent self-concept formation. 1990.

[7] Williams, G.C., et al., Research on relationship-centered care and healthcare outcomes from the Rochester Biopsychosocial Program: a self-determination theory integration. Families, Systems, \& Health, 2000. 18(1): p. 79.

[8] Frankl, V.E., The will to meaning: Foundations and applications of logotherapy. 2014: Penguin.

[9] Aslani, Y., Etemadyfar, S., \&Noryan K. (2010). Nurses' knowledge of blood transfusion in medical training centers of Shahrekord University of Me dical Science in 2004, IJNMR; 15(3): pp.141-144.

[10] Fatemeh Soleimani Ahmadi S. Abdolvahab Samavi, Samaneh Najarpourian. Evaluating the Effectiveness of Logo therapy on the Increase of Positive Self-Concept and General Health of the Thalassemia Patients. American Journal of Life Science Researches 2017; 5(4): 184-192.

[11] American Nursing Association. (2014). Connection between nurse staffing and patient outcomes can be made in all hospital clinical areas with expanded measures. Available at: www.nursingworld.org.

[12] Ndambuki, J. (2013). The level of patients' satisfaction and perception on quality of nursing services in the Renal Unit, Kenyatta National Hospital Nairobi, Kenya. From patient satisfaction. Open Journal of Nursing; 3: 186-194.

[13] Taher, A., Vichinsky, E., Musallam, K., Cappellini, M., \& Viprakasit, V. (2012). Guidelines for the management of nontransfusion dependent Thalassemia (NTDT). Thalassaemia International Federation. Available at: www.thalassaemia.org.cy.

[14] National Heart L and Blood Institute (NHLBI). (2013): What Are Thalassemias? Health Topics 2013 [cited 20147 Dec]; Blood Diseases and Disorders]. Available from: http://www.nhlbi.nih.gov/ health / healthtopics / topics / thalassea.

[15] Hijji, M.B., Oweis, A.E., \& Dabbour, R.S. (2012). Measuring knowledge of blood transfusion: A survey of Jordanian Nurses.
American International Journal of Contemporary Research, October; 2: 10.

[16] Taylor, C. Lillis, C., LeMone, P., Lynn, P. (2008). Fundamental of nursing, the art and science of nursing care, (6th ed.). Lippincott William and Wilkins, Philadelphia, pp.570-582.

[17] Risser, N. (1975). Development of an instrument to measure patient satisfaction with nurses and nursing care in primary care.

[18] Campbell, J. D., Trapnell, P. D., Heine, S. J., Katz, I. M., Lavallee, L. F., \& Lehman, D. R. (1996). Self-concept clarity: Measurement, personality correlates, and cultural boundaries. Journal of Personality and Social Psychology, 70(1), 141-156.

[19] Elsayed, L.A., \& Abd El-Gawad, S.M. (2015). Nursing guidelines for children suffering from beta thalassemia. International Journal of Nursing Science; 5(4): 131-135.

[20] Elewa A.E \& Ahmed A.A. (2017): Effect of an Educational Program on Improving Quality of Nursing Care of Patients with Thalassemia Major as Regards Blood Transfusion. American Journal of Nursing Research, 2017, Vol. 5, No. 1, 13-21 Available online at http ://pubs .sciepub .com /ajnr /5/1/2 OScience and Education Publishing.

[21] Elkattan, B. (2013): Impact of training program regarding for neurological patients in coma upon nurses' performance. Doctoral Thesisin Nursing Science, faculty of Nursing, AinShams University, p. 120 .

[22] Salem, B. (2013). Evidence-based guideline for care of neonates with respiratory distress. Doctorate in Nursing Science Thesis, Medical-Surgical Nursing, Faculty of Nursing, Ain Shams University, Cairo, pp.143-144.

[23] Northern California Comprehensive Thalassemia Center. (2012). UCSF Benioff Children's Hospital Oakland Available at: thalassemia.com/treatment-transfusion.aspx.

[24] Khouri, R.I. (2011). Impact of an education program on nursing students caring \& self-perception in intensive clinical training in Jordan. Depress Browse Journal. Advances in Medical Education and Practice. 2:.173-185.

[25] Alomar, H. (2012). Assessment of nurse's performance for caring of patients in mechanical ventilator. Master Science in Nursing Degree, Faculty of Nursing, Ain Shams University, pp. 102-153.

[26] Deborah, J.A., \& Corcoran, F. (2011). Acute undifferentiated leukemia in adults, (7th ed.) Hong Kong: Excel Typesetter, pp.380-400.

[27] Karimi, S. and M. Memarzadeh, The Effects of Logotherapy on Self-Concept Scale in Iranian Leukemia Patients: Seyed Alshohada Hospital in Isfahan Province. International Journal of Humanities and Cultural Studies (IJHCS) ISSN 2356-5926, 2016. 1(1): p. 2113-2119.

[28] Messina G, Colombo E, Cassinerio E, Ferri F, et al. (2008). Psychosocial aspects and psychiatric disorders in young adult with thalassemia major. Intern Emerg Med. 3(4): 339-343.

[29] Tahmasebi S, Ghofranipoor F, Ravaghi K. (2005). Effectiveness of group discussion on body image in adolescents (11-18 years) with thalassemia. Shahrekord Univ Med Sci J. 7(4): 50-7. [Google Scholar].

[30] Hunter, K. (2010). Nursing skills. The importance of practical experience. Available at: http://ezinearticles.com/? Nursing-SkillsThe-Importance-of-Practical-Experience $\&$ id=3797. 